\title{
Teaching Macro Social Work through Experiential Learning: Student Reflections on Lessons Learned in Building School-Community Partnerships
}

\author{
Lisa V. Blitz \\ Denise Yull \\ Martha G. Solá \\ John E. Jones
}

\begin{abstract}
A faculty-led experiential learning project was implemented with Master of Social Work students at their field placement sites to teach macro practice skills and research methods. As part of a grant-funded school-university partnership, MSW students were placed in school social work field placements, where their practice focused on individual and small group interventions with youth. Ten MSW students participated in asset-based collective family engagement in diverse, low-income communities, using community organizing skills and community-based participatory research methods. To examine student learning, a pilot study gathered narrative data from seven of the students and three supervisors. MSW students' learning from the project is discussed in the context of CSWE's 2015 EPAS competencies. Participation in the experiential/service-learning project supported the ability of the MSW students to build a sense of themselves as professionals bringing value to the community, enhanced their understanding of cultural diversity and family engagement, and provided context for vulnerable students' struggles in school and the families' difficulties with school engagement. This project illustrates the potential of school-university partnerships involving MSW field students to help bridge the gaps in school-family partnerships, particularly in diverse and low-income communities, and highlights areas where different teaching methods can be used to reinforce competencies learned.
\end{abstract}

Keywords: Experiential learning; service learning; field education; school-community partnership; macro social work; community organizing; participatory research; family engagement

Considered the primary pedagogy of social work, field education provides students opportunities to develop a full range of practice skills, and all social work competencies are expected to be taught and evaluated in field (Council on Social Work Education [CSWE], 2015). The emphasis on field education validates the importance of experiential learning to help social work students apply theory to practice and develop skills necessary for their professional development (Carey, 2007). Each field placement, however, is necessarily focused on helping students develop skills related to the primary service focus of the organization. Experiential learning that takes place at the internship site, but includes activities distinct from the typical fieldwork responsibilities of that organization, can enhance students' education and add depth to their experience with a wider range of social justice issues (Cramer, Ryosho, \& Nguyen, 2012).

Lisa V. Blitz, PhD, LCSW-R, is an Associate Professor, Department of Social Work, College of Community and Public Affairs, Binghamton University, Binghamton, NY 13902. Denise Yull, EdD, is an Assistant Professor, Department of Human Development, College of Community and Public Affairs, Binghamton University, Binghamton, NY 13902. Martha G. Solá, LCSW-R, is a former project supervisor and John E. Jones, LMSW, is a former social work intern with the project discussed in this manuscript. 
Social work students may struggle to understand how individual and family practice relates to macro work (Miller, Tice, \& Harnek Hall, 2008), and social work educators may struggle with teaching research, community work, and policy in ways that help students value these as relevant in social work practice (Sather, Weitz, \& Carlson, 2007). Experiential and service-learning is increasingly used to teach macro-level knowledge and skills (Bringle \& Steinberg, 2010; Lemieux \& Allen, 2007) and can be particularly beneficial in teaching practice competencies that may not be emphasized in traditional field placements. When engaged in experiential learning, social work students increase competency in areas such as research (Jacobson \& Goheen, 2006), data-driven practice (Shaw, Lee, \& Wulczyn, 2012), and policy practice (Rocha, 2000). Additionally, evaluation of social work student learning is increasingly focused on observation of students' competency in practice skills (CSWE, 2015), however, observing macro social work skills can be challenging in classroom-based instruction.

Different models of experiential learning include activities that emphasize selfdiscovery, which often involve class or group projects, and those which take students outside of the classroom to gain knowledge and develop awareness of people and communities (Cramer et al., 2012). Teaching research methods, community organizing skills, and policy issues through experiential learning in tandem with traditional field placements is a method of teaching that engages students in learning macro skills. This paper describes one such project, conducted with Master of Social Work (MSW) students at their social work field placements in public middle schools. The focus of this paper is on the MSW students' learning in the context of the related 2015 Educational Policy and Accreditation Standards (EPAS) competencies (CSWE, 2015). The project is described to give context to the students' educational experiences. Students' reflections on their learning illustrate how participation in the project taught and reinforced macro social work competencies. Highlights are shared regarding different teaching strategies that may help MSW students develop macro practice skills.

\section{Benefits of Experiential and Service-Learning}

Universities can create a lasting impact in the community through deep engagement and a commitment to using university resources for community transformation through community-based experiential learning projects (Kronick \& Cunningham, 2013). For social work students, experiential learning can be transformative. Some students come to their MSW program with limited exposure to critical reflection about social justice issues and scant knowledge of how equity ideals can be put into action (Jones, 2009). Experiential learning that contributes to social change and centers around reflection on the process provides in-vivo teaching opportunities to facilitate students' learning. Students engaged in experiential learning show increased self-awareness and improved cultural competency (Pugh, 2014), have a more nuanced understanding of the population (Cheek, Rector, \& Davis, 2007), and also show a more complex understanding of, and commitment to, social justice (Cramer et al., 2012).

Experiential education can take the form of service-learning. Student reflection on the learning activities and their role in the community is critical to service-learning, a process that promotes students' civic responsibility (Bringle \& Steinberg, 2010). The combination 
of engagement and reflection central to service-learning can also add to students' learning in other areas, as it helps develop their abilities in critical thinking and challenges them to understand and respond to complex social problems (Eyler, 2009). Service-learning can be used to teach and reinforce social work values, such as strengths-based perspectives, empowerment, anti-oppressive principles, and asset-based citizen-driven approaches (Donaldson \& Daughtery, 2011). Service-learning can also help reinforce students' mastery of practice competencies by providing opportunities to use skills differently than what may be used in their field placement (Phillips, 2011). A distinguishing feature of service-learning, however, is the emphasis on the reciprocal nature of the project. Students are engaged in learning for themselves, but their role is defined by the needs of the community. Integrating service-learning into fieldwork practice thus requires flexibility in defining the nature and goals of the project (Lemieux \& Allen, 2007).

\section{Experiential Learning and University Partnership for K-12 Education}

Universities are increasingly prioritizing engagement with public schools to address problems in primary and secondary education (Harkavy, Hartley, Axelroth Hodges, \& Weeks, 2013). Family engagement is one area in which a university partnership can be valuable. Family engagement is a central component of student achievement (Karbach, Gottschling, Spengler, Hegewald, \& Spinath, 2013), but these initiatives are often difficult for schools to take on alone.

Traditional models of parent involvement in schools often do not respond effectively to financially poor families, families of color, or those from diverse cultural backgrounds (Baquedano-López, Alexander, \& Hernandez, 2013). Families who live with poverty are particularly vulnerable as they are likely to have higher exposure to multiple stressors contributing to physical and mental health concerns that make engagement with their children's schools difficult (Blitz, Kida, Gresham, \& Bronstein, 2013). University partners who develop relationships with marginalized families can act as liaisons to help bridge gaps between home and school (Sanders, 2008) and create opportunities for new ways to understand complex problems. In the project described here, MSW students conducted family engagement outreach led by their field instructor and university faculty as part of a school-university partnership.

\section{Description of the Communities and Project}

In 2009, a federal Safe Schools/Healthy Students grant was awarded to a cooperative of educational services to initiate a school-university partnership to address a range of school concerns, including family engagement, for the region. The university was a subcontractor on the grant and hired licensed master's-level social workers to act as project supervisors and field instructors for MSW students placed in local schools, working alongside the school social workers. Three project supervisors each led a team of four to seven MSW students who were placed in a middle school, serving grades 6 through 8 , for two days per week. These teams added social work capacity to the school and enhanced the visibility of social workers as change agents in school improvement.

Engaging families of vulnerable students was a priority identified by the school 
districts that participated in this project, which included three geographically contiguous school districts in the Northeast United States. To protect the identity of the school districts, specific citations are not provided for community or school data. The school districts radiated outward from an urban school district, a small city where more than $75 \%$ of students in the district were economically disadvantaged and about $50 \%$ were people of color. In suburban district 1 (SD1), over $70 \%$ of students were economically disadvantaged and just over $35 \%$ were people of color. In suburban district 2 (SD2), 50\% of students were economically disadvantaged and $20 \%$ were people of color. Each district struggled with disproportionately negative outcomes, including lower graduation rates and higher discipline referrals, for students of color and financially poor students when compared to white students and those who were not financially disadvantaged in the same district.

MSW students' field placement responsibilities were primarily traditional school social work tasks: individual and small group counseling with students, collaboration with school- and community-based mental health professionals, and consultation with the parents of the students on their caseloads. Working closely with school social workers, building administrators, guidance counselors, and teachers, the project's social work supervisors and university faculty established relationships to form foundations for innovation directed at improving student achievement and eliminating disproportionally negative outcomes for vulnerable students. A faculty member from the department of social work led the project, and a team of seven other faculty from the university's department of social work, department of human development, the school of education, and the school of nursing collaborated on other interconnected projects aimed at similar goals.

Project supervisors led efforts in family engagement that were directed toward families identified by the schools as hard-to-reach and whose children were struggling academically and/or socially. To better understand the experiences, strengths, and needs of these families and to enhance partnerships, three of the project teams worked with university faculty to conduct outreach with families. The outreach was informed by community-based participatory research methods ([CBPR] Bermúdez Parsai, Gonzalez Castro, Marsiglia, Harthun, \& Valdez, 2011) and asset-based community organizing principles (Bauer, Kniffin, \& Priest, 2015).

For the MSW students, these responsibilities were framed as experiential/servicelearning designed to give them the experience of macro social work practice through activities that were outside of typical fieldwork tasks. In the initial phases of the project described here, the full criteria for service-learning as described in this paper were not met, which led to the characterization of the project as experiential/service-learning. School community was defined as the school and the neighborhoods surrounding it. It includes both the physical buildings and the people--staff, students and their families, as well as neighbors, who used them. There was reciprocal benefit between MSW students and the school building communities, but the reciprocity with the neighborhood communities was not yet developed. Further, the experiential/service-learning project did not add additional Pacademic instruction beyond the students' MSW coursework, a central component of service-learning. The project did, however, provide numerous opportunities for reflection and civic engagement for MSW students. The project also laid the groundwork for family engagement that incorporates reciprocal benefit among schools, families, and later groups 
of MSW students who take on the next stages of the work.

Experiential Learning and EPAS Competencies. Consistent with service-learning, the project was developed around the schools' goal of engaging families rather than being driven by a faculty research agenda. Since the project worked in tandem with the MSW students' field placements, it was expected that all EPAS competencies would be addressed. As the project developed, however, there were some competencies that were emphasized more than others in the experiential/service-learning.

Since the project involved outreach to families in diverse communities, MSW students developed skills for both competencies 2, "engage diversity and difference in practice" (CSWE, 2015, p. 7), and 6, "engage with individuals, families, groups, organizations, and communities" (CSWE, 2015, p. 8). The families lived with financial hardship, and during the outreach families would often discuss their experiences of individual bias and systemic inequities, supporting the MSW students' learning for competency 3, "advance human rights and social, economic, and environmental justice". Since the students were assisting in a CBPR project, competency 4, "engage in practice-informed research and researchinformed practice", was supported through training in the research protocol and gathering, organizing, and analyzing data. Finally, in the larger context of the family engagement project, the MSW students had experience with competency 5, "engage in policy practice", as they were part of discussions about changes needed in existing social service and school policies to effectively meet families' needs and helped develop recommendations to the school districts.

\section{Methods of Inquiry Taught to MSW Students: CBPR and Community Organizing}

The faculty member who acted as principal investigator (PI) on the family engagement research trained three project supervisors and $10 \mathrm{MSW}$ students (the project teams) in the research protocol and guided them in the research process, including integrating social work theory and practice. The students were both foundation (first year) and concentration (second year) students in an advanced generalist social work program. Each year of their social work education included courses in research and macro practice, and the experiential/service-learning focused on practice competencies commensurate with their course work and EPAS standards.

The project extended over both the fall and spring semesters. In the fall semester, prior to being included as research assistants on the human subjects review board protocol, the project supervisors and MSW students took the online Collaborative Institutional Training Initiative (CITI) research course. The PI trained the project team members in the research protocol in the fall semester and provided support throughout the academic year. MSW students and the project supervisors understood and agreed that as part of the CBPR process, their experiences and learning were also important data.

None of the project supervisors had participated in this type of research project before. Therefore, the PI worked closely with the project supervisors to build their confidence in their research skills and to ensure that the concepts and skills were reinforced with the MSW students. An important part of this process was for the PI to teach research interview skills to the project supervisors so they could, in turn, teach these skills to the MSW 
students. In contrast to social work practice skills, which may reach for feelings or encourage clients to focus on their own behaviors, research questioning focused on experiences, observations, and elaboration of opinion - a subtle but important difference for the supervisors and MSW students to understand.

The PI met with the supervisors weekly and had periodic meetings with the teams, but the project supervisors took the lead in the school district in which they worked. All team members were responsible for gathering, organizing, and analyzing data, as well as thinking about next steps in family engagement. The teams were more closely connected to the school they served and their local community than the PI. Therefore, the teams made decisions about the direction of the family engagement efforts informed by their experiences in the school and what they learned through the research process.

Consistent with CBPR and supporting deeper learning through experience, MSW students tracked the evolution of the project in each district through field notes and observations, adding to their understanding of families' strengths and needs. The MSW students worked closely with the school social workers, and their evolving understanding of families' concerns informed the schools' family engagement efforts. It was important that the research allow flexibility to meet the needs of the school community and the requirements of grant-funded services, which also contributed to reflections on the experiential/service-learning as it evolved. In meetings with all three teams together, MSW students had the opportunity to learn about the different trajectories of the project and discussed possible contributing factors. These discussions deepened the students' understanding of research-informed practice, community organizing, and the impact of school policies on family engagement.

\section{Parent Cafés: Asset-based Collective Family Engagement}

Family engagement was a service goal of the grant-funded program and supported the service-learning ethic of reciprocity by promoting student learning and benefiting the school community. Consistent with the MSW students' course work, the project involved philosophy of asset-based community development (ABCD; Kretzman \& McKnight, 1993). ABCD was developed as an alternative to needs-based approaches in which universities and/or community-based organizations intervene on behalf of a community to address problems defined by the outsiders. According to Kretzman and McKnight (1993), needs-based approaches tend to over-emphasize deficits and problems and can have the undesired effects of reducing motivation and self-agency and creating dependence on outside institutions. In contrast, the ABCD approach positions outside institutions as facilitators to uncover internal strengths and assets that community members can use to address the problems they define as needing attention. Although ABCD has been criticized for not attending to the macro-level causes of disempowerment, the focus on relationship and community-building can mobilize groups for collective action to address root causes of concerns (Ennis \& West, 2010).

The project adapted a Parent Café model, loosely based on the Community Café (National Alliance of Children's Trust and Prevention Funds, n.d.) and World Café models (Sheridan, Adams-Eaton, Trimble, Renton, \& Bertotti, 2010) to start conversations and 
build relationships among families. The Café models use a set of questions to guide structured conversations among community members. Along these lines and using a CBPR framework, MSW students were taught a grounded theory approach for initial inquiry, building conversations around grand tour questions (Faulkner \& Faulkner, 2014) aimed at understanding the parents' experiences in the community and with the school.

CBPR fit well with the Café model as the dual goals of data collection were to learn more about the families and bring them together to explore their interest in collective action (Berg \& Lune, 2012). Equally important, the Café model supported an orientation toward identifying common concerns and collective action centered on families' goals, not institutional priorities (Weiner, 2009). The conversations also promoted the asset-based philosophy that supports MSW students' ability to see families as equal partners in familyschool engagement (Bauer et al., 2015).

Project supervisors and MSW students began by conducting outreach to families of students referred by the school administration. The school administrators identified students who were in danger of not passing their grade or not graduating, often because of chronically low attendance, and students with multiple discipline referrals. Initial contacts were often made by phone, but direct outreach to the home was made when a family was difficult to reach. Visits to the families' homes were conducted in pairs, beginning with a project supervisor-MSW student pair. As the students gained skills and confidence, two students conducted outreach independent of the supervisor. Team members introduced themselves by stating they were working with a university project, noting that they worked with, but not for, the school, and their interest was in the parents' experiences and concerns with regard to their children. They obtained informed consent for the research prior to asking questions. MSW students took turns talking with the parent while the other team member took notes. Notes were reviewed with the parent at the end of the interview to ensure that the answers were recorded accurately, as a form of member checking (Ely, Anzul, Friedman, Garner, \& Steinmetz, 1996), and to affirm the respect for the family member's opinion and experience.

The project teams contacted a total of 138 parents and custodial grandparents. Of these, 70 parents were contacted from the urban school district, 31 from SD1, and 37 from SD2. Just under half of the total group of parents were people of color and about one-third lived in two-parent families. There was no intent to focus on students from financially poor families, but in each school district all of the families contacted were economically disadvantaged.

The project team used the interviews with parents to stimulate interest in collective action, requiring the MSW students to use community organizing and research skills simultaneously. The team asked parents if they were interested in hosting a Parent Café, which involved the parent inviting five to seven friends or neighbors who also had children in the district to meet and discuss school concerns. This snowball technique provided access to parents who might otherwise not have been interested in working with social workers. If the parent was interested in hosting a Parent Café, a member of the team, usually the MSW student, followed up and helped organize the meeting. Since the MSW students only worked with the project two days per week for the academic year, the project 
supervisors and school social workers assumed responsibility for maintaining contact with families and building relationships that extended beyond MSW students' time in their field placement.

The initial Parent Café meetings were organized as focus groups facilitated by the project team. The teams organized five Parent Café focus groups in the urban district, three in SD1, and one in SD2, totaling nine Parent Café focus groups. Meetings were held at various locations convenient to the families, including a community library, a church meeting room, and families' homes. Each group explored the parents' perspectives regarding their child's education and their experiences with the school. One of the team members took notes and checked with Café members to ensure accuracy of the responses. Parents received a $\$ 50$ gift card to a local store for hosting a Parent Café, and group members received a $\$ 10$ gift card for attending the first Café meeting. At the end of the Café, the group discussed the possibility of future meetings to identify a goal or project the group wanted to complete or to discuss inviting school personnel to join them to talk about a concern. If the group was interested, the team worked with them to plan and organize future meetings. Future meetings focused on understanding issues from multiple perspectives, identifying community assets, and developing strength-based solutions to problems, more fully actualizing the ABCD model. As relationships and trust developed, the project team members functioned as liaisons among parents, school personnel, and community resources. Some parents invited school personnel to join their conversations, and school personnel understood the Parent Café as a method of accessing and communicating with parents (see Yull, Blitz, Thompson, \& Murray, 2014).

\section{Learning from Data and Taking Action}

In debriefings with the project supervisor following the outreach into the community, the MSW students reflected on their experience, discussing their impressions and reactions to what they heard and saw. The teams reviewed the notes taken during individual meetings with parents and the Parent Café focus groups and began developing open codes that formed a foundation for later analysis (Sherman \& Reid, 1994). Data were combined from the individual interviews and the Parent Café focus groups but kept separate for each school district. Each team worked to understand the themes that evolved from the outreach in their school district and used this to inform next steps in the family engagement process. Through this process, the project supervisors taught and modeled research-informed practice and practice-informed research.

Toward the end of the spring semester, when the bulk of the data had been collected and initial analysis had been conducted, the PI met with each team to begin the next phase of analysis. In this process, the PI reviewed the notes from the debriefing sessions with each project team, discussed the initial codes from the data they collected, and together they categorized the information into themes. The triangulation process, with data examined by multiple people from different perspectives to arrive at a collective understanding about the meaning, helped to ensure the trustworthiness of the findings (Ely et al., 1996). Furthermore, it taught MSW students qualitative analysis techniques and led to discussions about dependability and transferability of findings (Guba, 1981). At the end of the academic year, the PI, project supervisors, and MSW students presented district- 
specific data to the administrative team in each school district, providing opportunities for the MSW students to think through the policy implications of the findings and develop recommendations for school district administration.

In debriefings with their supervisor, MSW students were encouraged to think about their experiences in the community in relationship to their work at the school and their academic lessons in classes. Discussion often focused on policies related to education and social services, school expectations and norms, and various degrees of fit and disconnection between the policies and the parents with whom they engaged. MSW students were also encouraged to critique the research methods and processes to identify strengths and limitations of the techniques for gathering meaningful data. These conversations helped MSW students link their experiential knowledge to macro issues, such as school policies, mental health policy and service availability, housing and tenant concerns, public assistance, and child protective services.

\section{Macro Social Work in Action: Lessons Learned by MSW students}

The reflections on MSW student learning presented here come from conversations and email exchanges with the PI approximately six months after the MSW students had completed the project and the fieldwork placement. Separate human subjects review board approval was obtained to include the MSW students' reflections on their learning. Ten MSW students participated in the project, and the experiences of seven of them are reflected here. The other three had graduated and were not available. All the students who participated in the follow-up interviews were people of color, and several grew up in financially poor communities of color in urban areas. Four of the students, two male and two female, were in their early 20 s and had very limited adult experiences in their home communities. The other three, one male and two female, were older and had returned to school after a variety of professional and other life experiences. Of the project supervisors all were female; one was Black, one Latina, and one White.

The interviews were conducted by the PI in a semi-structured format where the former MSW student participants were asked to reflect on their experiences and talk about what they learned. They were informed that the PI, another researcher, a project supervisor, and a former MSW student who worked on the project (the research group) wanted to understand what the students had learned and would be developing a manuscript for publication. Following the interviews, several of the former MSW students followed up by email to share additional thoughts and experiences. Notes from the conversations and the text of emails were compiled by the PI and checked with the former MSW students to ensure accuracy. De-identified notes were then studied by the research group, which used EPAS competencies as a priori codes.

By reviewing the comments, the research group identified that the former MSW students' learning in competencies 2 , "engage diversity and difference in practice" (CSWE, 2015 , p. 7), and 6, "engage with individuals, families, groups, organizations, and communities" (CSWE, 2015, p. 8) were clearly enhanced by their participation in the project. Three additional EPAS competencies were noted as showing indications of some growth, but practice skills were not clearly developed. 


\section{EPAS Competency 2: Engage Diversity and Difference in Practice}

Regardless of their personal identity and experience, all the students noted that the community outreach expanded the range of families and community stakeholders with whom they had contact. The exposure to ethnically diverse families in their homes and community helped the students understand and practice culturally responsive approaches and enhanced their social work skills. As noted by one student, "Family engagement gave me direct exposure to at least three different ethnic families: White, Black, and Hispanic. To me, this was remarkable because I was able to differentiate between my ability to communicate with each of the ethnic families."

The one thing all the MSW students had in common was that they were people of color for whom education had been a vehicle for self-improvement and advancement. Their own success informed their worldviews and often mediated their personal experience of oppression. They were often surprised by how racism impacted the lives of the families they met and how families were frequently reluctant to talk about the issues even when the outreach worker was also a person of color. One MSW student recounted:

[Parents] had the hardest time talking about race and culture, I think because they didn't trust outsiders. When they did open up they had so many stories about things that had happened to them, things I was not aware of. I didn't realize these things were happening.

For some MSW students, hearing the families' experiences of racial bias and the impact of oppression brought up complicated feelings about their own situation or life issues with which friends or family members struggled. Students' awareness of how race and cultural issues played out in the schools was also heightened. They developed a greater understanding of the need for in-depth education regarding race, oppression, and privilege for school personnel to better understand the students and their families. As one MSW student stated, "The training on cultural competency that the teachers get just doesn't go far enough for them to really understand what kids live with every day." Another student noted, "I didn't know how serious [racism] is, I didn't realize how much people just don't know."

The students often reflected on the difference between the race-aware education they received in their social work curricula and the colorblind perspective maintained by many school personnel. One student noted that:

Lack of education around race really affects education; it limits how effective education is. Race is a part of everything, a part of the education experience. If the school administrators and teachers don't understand that then too much gets lost or misunderstood.

One student reflected on how different understandings of race and culture directly impacted communication among parents and school personnel. As he noted,

The education around race is so limited it skews our understanding about what is going on. If a parent has one perspective on race relations, and the kid has a different perspective, and the school personnel have a different idea, it skews how they 
understand how race impacts what is happening.

Another student considered how both school personnel and parents may bring preconceived notions of one another into their encounters. He noted that some parents may be skeptical of school personnel because of past negative experiences. For the MSW student, analyzing how race and culture-bound experiences strained the relationships was imperative. He recalled an example where school personnel mistook one Black male student for another in a discipline issue and were not sensitive to how this mirrored the kind of generalizations and stereotyping that Black people struggle against in our society. In talking about this incident, the MSW student noted:

In the end it turned out that the student had been mistaken for someone else. The school personnel not only didn't call and apologize to the parent, but weren't polite when the parent called. They didn't realize how hurt the dad was. These are the kinds of experiences parents bring with them when they engage with school staff.

\section{EPAS Competency 6: Engage with Individuals, Families, Groups, Organizations, and Communities}

While the MSW students were interested in community outreach, in the beginning many were tentative and afraid. As noted by one, "Initially, it was overwhelming and scary because I'd never done anything like it before." But by the time the project was underway, they expressed enthusiasm for the work. As they spent time out in the community talking to families, many MSW students also began spontaneously reaching out to local agencies in the area in an effort to understand the community service networks. As they did so, they began to see the power of partnerships among parents, schools, and community organizations. As noted by one student, "What was outstanding for me was the effort to get the community involved in the affairs of the school for the welfare of school children." Others noted the benefit of engaging with multiple organizations as a result of the outreach with parents. As one student stated, "I got to know the program directors of the different agencies around here and in the community as a whole. That helped me make professional connections even beyond my field placement."

The MSW students frequently talked about the need to bridge gaps between home and school. For some, the primary lesson learned was about understanding multiple perspectives of complex issues. For example, one student stated, "What struck me was that it's not that teachers don't care; the teachers care and the parents care too, but it's frustrating trying to bridge that gap." This concern was mirrored in another student's comment, "Bridging gaps has to be the most pivotal lesson learned. There are always two sides to a story and bridging those two stories is difficult." Others demonstrated an appreciation of their role in helping to be the bridge between families and schools. For example, one MSW student discussed the sense that some families experienced school personnel as punitive which inhibited engagement. The project team's asset-based focus was better received. As one student observed, "When the school official goes out they are the authority, talking about what is going wrong. When we went out we could focus on building relationships...The families were so much more receptive after that, more 
welcoming."

MSW students also came to appreciate the importance of developing relationships with community leaders and stakeholders and learned the power of community work. Engagement with families provided a chance to get to know the community from a different perspective and created opportunities for learning about community resources. One student stated, "It was a great opportunity to get to know the community better. I learned a lot about the different agencies in the area, different organizations for afterschool care. That helped me help make those connections for the parents." Other students developed a passion for community work, discovering an important avenue for their careers. As one stated enthusiastically:

Community work is highly effective and important. I absolutely love community work. A social worker cannot, the government cannot, those in power cannot identify the needs of a community of which they are not a part, nor will the community be receptive to your insight.

\section{Lessons Learned-But Were Competencies Developed?}

In addition to clearly learning and using skills related to competencies 2 and 6, the former students indicated advancement in their understanding in other areas. However, their ability to translate learning into practice was less clear. EPAS competency 3, "advance human rights and social, economic, and environmental justice" (CSWE, 2015, p. 7), was one such area. Effective advocacy or other action to advance human rights and work for justice requires a genuine understanding of the issues from the points of view of the people who are affected. While it is not clear whether the MSW students' were able to take action, their deepened awareness of social justice concerns was evident. Hearing about family and community problems is often difficult, especially for students, and the outreach put students in the middle of neighborhoods where these problems were the most concentrated. The immersion created struggles with maintaining a strengths-based perspective, as noted by one student:

I began to hear all of these horror stories and concerns, so much that strengths about the community and schools became unimportant. I would minimize those strengths but then stress and harp on the negatives. It is easy to get caught in the negatives of situations versus highlighting the positives.

Another MSW student noted how seeing the living conditions changed the way she looked at students' struggles in school, "There were so many needs. It helped put everything in perspective. How can they come to school and perform like everybody else when they have so much to deal with at home?"

Seeing the lived experience of oppression was profound for the MSW students, and understanding the ripple effects of marginalization on a family's life was a key lesson. As one student stated, "I was surprised about how many times [the families] did not use a service in the community because they did not think it was for them or they didn't think they would fit in." Students also talked about how impressed they were that families who felt ostracized by their community actually wanted to be engaged. As noted by one student, 
"The people in the community have so much to say about the issues. They not only have concerns but they also have insight and ideas on what can be done to change these issues." Another student noted, "The families want some control; they want to be part of the solution. They don't want someone to come in and tell them what the solution is."

Learning in EPAS competency 4, "engage in practice-informed research and researchinformed practice" (CSWE, 2015, p. 8), was also enhanced, but the extent to which the MSW students developed competency in this area was less clear. Each of the MSW students expressed that the project provided them with fundamentally different experiences than what they would have had if they had only participated in a school social work field placement, and they were glad to have had the experience. All expressed surprise that research could be so relevant to the immediate needs of families and schools.

Two observations were made by the PI. First, although the project supervisors maintained a clear sense that they were participating in a research project and that information gathered was research data - and this clearly felt different to them- the MSW students approached the work as simply a social work project. For the students, collecting and using data to develop programming and inform school policies and initiatives seemed natural and fit well with what they were being taught in class as best practices. Second, during team meetings to discuss the data, identify themes, and critique the CBPR process, the MSW students clearly showed that they understood research concepts and could use research skills. Yet when asked about the project, none of them talked about specific learning related to research methods. Although the extent to which research methods were learned or retained is not clear, it is clear that research was experienced as a natural and important part of practice.

Finally, students' learning in EPAS competency 5, "engage in policy practice" (CSWE, 2015 , p. 8), was another area where progress in understanding was seen but practice skills were not clearly developed. The impact of the students' learning around issues of diversity was profound, multifaceted, and included issues related to policy. Hearing stories about how systems were not working for families prompted students to learn more about the social service and mental health systems locally and nationally. Students began considering the policies behind the practice and questioned why some families did not or could not access services. Seeing how many parents had good ideas to solve community problems also prompted students to learn and understand obstacles to getting those ideas heard and acted upon within the schools and the community at large.

The project gave the MSW students exposure to other facets of the lives of the middle school students they worked with in the school. This exposure helped them understand some of the school policy issues that created barriers for families, and they were able to talk about these with the school social worker and other school personnel. As one student stated,

It made me better able to talk to the school about the student's problems, especially with attendance. I could advocate better for the student and help the school understand why it was so hard for the kid to come to school every day.

Other students reflected on their learning about systems functioning and the importance of 
communication among the different people involved. As noted by one student:

I learned that you can't, as social workers, just go into the school and do individual treatment with the kids and think that's going to work to solve all the problems...But if all parties come together, administrators, teachers, social workers, afterschool programs, and work together, then the needs of the whole child and the whole family can be met.

\section{Discussion}

Participation in the experiential/service-learning project supported the ability of the MSW students to build a sense of themselves as professionals bringing value to the community. The experience added to their knowledge about the diverse families and communities they served in their fieldwork and provided opportunities to learn community outreach and organizing skills as well as participatory research methods. The project also provided numerous opportunities for field instructors and faculty to observe EPAS competencies in action and enriched the field instruction experience.

In generalist social work education and practice, social workers need to think critically and dynamically, using micro-, mezzo-, and macro-level social work skills interactively, which can be challenging during the learning process (Miller et al., 2008). In this project, the MSW students saw the impact of social and economic oppression firsthand by spending time in the community with students and their families, witnessing situations and events that their young clients rarely talked about when in school. Through this process, the intersection of individual troubles and environmental factors that made daily survival difficult became obvious, and sometimes even painful, for the MSW students to face. Identifying community assets can be difficult for students confronted with enormous troubles and needs (Green, 2015), and some of the MSW students in this project discussed that struggle. The project's asset-based approach, however, helped them learn to identify community and individual strengths, making this an important method for communitybased experiential and service-learning projects (Bauer et al., 2015).

As seen in similar projects, the experience enhanced the MSW students' understanding of cultural diversity and family engagement (Belliveau, 2011) and provided context for vulnerable students' struggles in school and the families' difficulties with school engagement. Further, the MSW students developed enthusiasm for macro social work, supporting their commitment to act as agents of social change (Kronick \& Cunningham, 2013). The MSW students' reflections also confirm previous findings that the experiential/service-learning project reinforced social work values of strengths- and assetbased perspectives and citizen-driven approaches to understanding and responding to community concerns (Donaldson \& Daughtery, 2011).

The students' reflections showed they understood the concepts and used the skills for EPAS competencies 2, "engage diversity and difference in practice" (CSWE, 2015, p. 7), and 6, "engage with individuals, families, groups, organizations, and communities" (CSWE, 2015, p. 8). Although the students had been instructed and supported in learning skills related to other macro competencies, the extent to which they developed competency was less clear when they talked about their experiences. Much of their reflections focused 
on the aspects that had been the most emotionally compelling, emphasizing that their learning was profound, and that connections made with families were poignant. It may be that the emotional development that took place during the learning process overshadowed developing practice skills, or that there was simply not enough time for them to turn their thinking and feeling into action. It is also possible that the competencies were developed but not part of what students chose to share when reflecting on the experience.

All the MSW students came away from the experience clear about the need for social work advocacy to enhance social and economic justice. The project exposed them to what social justice advocacy can look like in practice, providing a foundation for further skill development. It is important to note that, in contrast to other projects (see Rocha, 2000), the MSW students' engagement in policy work and actions to advance human rights and social justice were not as clear as their increased understanding and interest in doing this work. Action for social justice sometimes requires confrontation and willingness to disagree with those in authority. The skills required to do this effectively can feel as though they are in contrast to the engagement and collaborative strategies used in community development and may need differentiated field instruction for optimal skill development (Hardina \& Obel-Jorgensen, 2009).

The MSW students' complex connections with the diverse families and community members encouraged them to advocate for families in the schools and helped them understand policy and develop commitments to advance social justice. One aspect that was not mentioned by MSW students, but which made an impact on a project supervisor (and co-author), was the importance of discussions around language in debriefing sessions with MSW students. Schools require the use of Standard American English (SAE), which was often not used by the families contacted through the outreach. MSW students and their supervisors explored the possibility that the demand to use SAE could be experienced as a tool of hegemony by some families and the choice to use ethnic-identified English could be a form of healthy resistance (see Cunningham, 2014). Considering that MSW students were all very successful in scholarly pursuits and valued ways of knowing and communicating that were rewarded in academia, these insights were valuable in preparing them to move beyond the academy and into social work practice.

By collecting, analyzing, and interpreting data at each step of the family engagement process, consistent with similar projects (Shannon, Kim, \& Robinson, 2012), the MSW students were able to experience research-in-action making the empirical process accessible and relevant. Although others have found that engagement in experiential learning increased social work students' competency in practice-informed research and research-informed practice (Jacobson \& Goheen, 2006; Shaw et al., 2012), the evidence here was not clear. The PI observed the students using the related skills during the project, but they did not reflect on this in the follow-up. Again, the emotional impact of the experience may have outshone reflections on research. It is also possible, however, that following their participation in the project, research concepts were not retained or seemed less relevant than other aspects of practice.

There are limitations to assessing EPAS competencies though the process of semistructured interviews asking MSW students to reflect on their learning. The emotional 
impact of the experience may have ultimately been more memorable, and overall professional development more meaningful, than the specific skills acquired. All the MSW students in this project received strong positive feedback from their field instructors, and field evaluations showed that they did ultimately develop all the EPAS social work competencies. It may be that it was difficult to discern where and how specific skills were learned since they were used across multiple practice areas. It is also possible, however, that some competencies developed in field were not retained if they were not currently being used. Pre- and post-test measures, with follow-up once the former students were in professional practice, is needed to better clarify the learning and retention of the full range of social work competencies.

Beyond the benefits to the MSW students, the project had other benefits as well. Linking the project with faculty service and research provided seamless connections that enhanced community service, faculty research, and student learning simultaneously (Flinders, Nicholson, Carlascio, \& Gilb, 2013). School-university partnerships seeking innovative solutions to complex problems may take years to develop as they achieve implementation milestones that add depth and capacity to services and program innovation (Anderson-Butcher et al., 2010). All three school districts remain actively involved with the school-university partnership work. Social work faculty and MSW student support is central to this process, and each district has multiple faculty-led projects, some of which have resulted in university faculty, school personnel, and community partners co-authoring scholarly papers and making joint presentations at professional conferences. Faculty continue to be engaged in consultation, professional development, and service-learning projects that work with social work field placements to enhance students' mastery of social work competencies. The project also points to the potential of school-university partnerships involving MSW field students to help bridge the gaps in school-family partnerships, particularly in diverse and low-income communities.

\section{References}

Anderson-Butcher, D., Lawson, H. A., Iachini, A., Bean, G., Flaspohler, P. D., \& Zulling, K. (2010). Capacity-related innovations resulting from the implementation of a community collaboration model for school improvement. Journal of Educational and Psychological Consultation, 20, 257-287. doi:http://dx.doi.org/10.1080/10474412.2010.500512

Baquedano-López, P., Alexander, R. A., \& Hernandez, S. J. (2013). Equity issues in parental and community involvement in schools: What teacher educators need to know. Review of Research in Education, 37, 149-182. doi:http://dx.doi.org/10.3102/0091732X12459718

Bauer, T., Kniffin, L. E., \& Priest, K. L. (2015). The future of service-learning and community engagement: Asset-based approaches to student learning in first-year courses. Michigan Journal of Community Service Learning, 22(1), 89-92.

Belliveau, M. (2011). Interdisciplinary service-learning: Building student competencies through the cross-cultural parent groups project. Advances in Social Work, 12(1), 7993. 
Bermúdez Parsai, M., González Castro, F., Marsiglia, F. F., Harthun, M. L., \& Valdez, H. (2011). Using community-based participatory research to create a culturally grounded intervention for parents and youth to prevent risky behaviors. Prevention Science, 12, 34-47. doi:http://dx.doi.org/10.1007/s11121-010-0188-z

Berg, B. L., \& Lune, H. (2012). Qualitative research methods for the social sciences. Upper Saddle River, NJ: Pearson.

Blitz, L. V., Kida, L., Gresham, M., \& Bronstein. L. (2013). Prevention through collaboration: Family engagement with rural schools and families living in poverty. Families in Society, 94(3), 157-165. doi:http://dx.doi.org/10.1606/1044-3894.4306

Bringle, R. G, \& Steinberg, K. (2010). Educating for informed community involvement. American Journal of Community Psychology, 46, 428-441. doi:http://dx.doi.org/10.1007/s10464-010-9340-y

Carey, L. A. (2007) Teaching macro practice. Journal of Teaching in Social Work, 27(12), 61-71. doi:http://dx.doi.org/10.1300/J067v27n01_04

Cheek, T., Rector, K., \& Davis, C. (2007). The Clothesline Project: An experiential learning project with MSW students. Journal of Teaching in Social Work, 27(1/2), 141-154. doi:http://dx.doi.org/10.1300/J067v27n01_09

Council on Social Work Education. (2015). 2015 Educational policy and accreditation standards for baccalaureate and master's social work programs. Retrieved from http://www.cswe.org/File.aspx?id=81660

Cramer, E. P., Ryosho, N., \& Nguyen, P. V. (2012). Using experiential exercises to teach about diversity, oppression, and social justice. Journal of Teaching in Social Work, 32, 1-13. doi:http://dx.doi.org/10.1080/08841233.2012.637463

Cunningham, J. M. (2014). Literacy and identity when approximating African American language on social network sites. Journal of Literacy and Technology, 15(2), 54-77.

Donaldson, L. P., \& Daughtery, L. (2011). Introducing asset-based models of social justice into service learning: A social work approach. Journal of Community Practice, 19(1), 80-99. doi:http://dx.doi.org/10.1080/10705422.2011.550262

Ely, M., Anzul, M., Friedman, T., Garner, D., \& Steinmetz, A. M. (1996). Doing qualitative research: Circles within circles. Bristol, PA: Falmer Press, Taylor \& Francis.

Ennis, G., \& West, D. (2010). Exploring the potential of social network analysis in assetbased community development practice and research. Australian Social Work, 63(4), 404-417. doi:http://dx.doi.org/10.1080/0312407X.2010.508167

Eyler, J. (2009). The power of experiential education. Liberal Education, 95(4), 24-31.

Faulkner, S. S., \& Faulkner, C. A. (2014). Research methods for social workers: A practice-based approach ( $2^{\text {nd }}$ ed.). Chicago, IL: Lyceum.

Flinders, B. A., Nicholson, L., Carlascio, A., \& Gilb, K. (2013). The partnership model 
for service-learning programs: A step-by-step approach. American Journal of Health Sciences, 4(2), 67-77. doi:http://dx.doi.org/10.19030/ajhs.v4i2.7760

Green, T. L. (2015). Places of inequality, places of possibility: Mapping “opportunity in geography" across urban school-communities. Urban Review, 47, 717-741. doi http://dx.doi.org/10.1007/s11256-015-0331-z

Guba, E. (1981). Criteria for assessing the trustworthiness of naturalistic inquiries. Educational Communication and Technology, 29, 75-91.

Hardina, D., \& Obel-Jorgensen, R. (2009). Increasing social action competency: A framework for supervision. Journal of Policy Practice, 8, 89-109. doi:http://dx.doi.org/10.1080/15588740902740074

Harkavy, I., Hartley, M., Axelroth Hodges, R., \& Weeks, J. (2013). The promise of university-assisted community schools to transform American schooling: A report from the field, 1985-2012. Peabody Journal of Education, 88(5), 525-540. doi:http://dx.doi.org/10.1080/0161956X.2013.834789

Jacobson, M., \& Goheen, A. (2006). Engaging students in research: A participatory BSW program evaluation. The Journal of Baccalaureate Social Work, 12(1), 87-104.

Jones, P. (2009). Teaching for change in social work: A discipline-based argument for the use of transformative approaches to teaching and learning. Journal of Transformative Education, 7(1), 8-25. doi:http://dx.doi.org/10.1177/1541344609338053

Karbach, J., Gottschling, J., Spengler, M., Hegewald, K., \& Spinath, F. M. (2013). Parental involvement and general cognitive ability as predictors of domain-specific academic achievement in early adolescence. Learning and Instruction, 23, 43-51. doi:http://dx.doi.org/10.1016/j.learninstruc.2012.09.004

Kretzmann, J., \& McKnight, J. (1993). Community building from the inside out: A path toward finding and mobilizing a community's assets. Skokie, IL: ACTA Publication.

Kronick, R. F., \& Cunningham, R. B. (2013). Service-learning: Some academic and community recommendations. Journal of Higher Education Outreach and Engagement, 17(3), 139-152.

Lemieux, C. M., \& Allen, P. D. (2007). Service learning in social work education: The state of knowledge, pedagogical practicalities, and practice conundrums. Journal of Social Work Education, 43(2), 309-326. doi:http://dx.doi.org/10.5175/JSWE.2007.200500548

Miller, S. E., Tice, C. J., \& Harnek Hall, D. M. (2008). The generalist model: Where do the micro and macro converge? Advances in Social Work, 9(2), 79-90.

National Alliance of Children's Trust and Prevention Funds. (n.d.). Community café: Changing the lives of children through conversations that matter. Retrieved from http://www.thecommunitycafe.com/documents/CC FAQ.pdf

Phillips, A. (2011). Service-learning and social work competency-based education: A 'goodness of fit'? Advances in Social Work, 12(1), 1-20. 
Pugh, G. L. (2014). Revisiting the pink triangle exercise: An exploration of experiential learning in graduate social work education. Journal of Teaching in Social Work, 34, 17-28. doi:http://dx.doi.org/10.1080/08841233.2013.863264

Rocha, C. J. (2000). Evaluating experiential teaching methods in a policy practice course: The case for service learning to increase political participation. Journal of Social Work Education, 36(1), 53-63.

Sanders, M. G. (2008). How parent liaisons can help bridge the home-school gap. The Journal of Educational Research, 101(5), 287-298. doi:http://dx.doi.org/10.3200/JOER.101.5.287-298

Sather, P., Weitz, B., \& Carlson, P. (2007). Engaging students in macro issues through community-based learning. Journal of Teaching in Social Work, 27(3-4), 61-79. doi:http://dx.doi.org/10.1300/J067v27n03 05

Shannon, P., Kim, W., \& Robinson, A. (2012). Implementing a service learning model for teaching research methods and program evaluation. Journal of Teaching in Social Work, 32(3), 229-242. doi:http://dx.doi.org/10.1080/08841233.2012.680867

Shaw, T. V., Lee, B. R., \& Wulczyn, F. (2012). "I thought I hated data": Preparing MSW students for data-driven practice. Journal of Teaching in Social Work, 32, 78-89. doi:http://dx.doi.org/10.1080/08841233.2012.640599

Sheridan, K., Adams-Eaton, F., Trimble, A., Renton, A., \& Bertotti, M. (2010). Community engagement using World Café: The Well London experience. Groupwork 20(3), 32-50. doi:http://dx.doi.org/10.1921/095182410X576840

Sherman, E., \& Reid, W. J. (Eds.). (1994). Qualitative research in social work. New York, NY: Columbia University Press.

Weiner, M. F. (2009). Elite versus grassroots: Disjunctures between parents' and civil rights organizations' demands for New York City's public schools. The Sociological Quarterly, 50, 89-119. doi:http://dx.doi.org/10.1111/j.1533-8525.2008.01134.x

Yull, D., Blitz, L. V., Thompson, T., \& Murray, C. (2014). Can we talk? Using community-based participatory action research to build family and school partnerships with families of color. School Community Journal, 24(2), 9-31.

\section{Author note:}

Address correspondence to: Lisa V Blitz, PhD, LCSW-R, Department of Social Work, College of Community and Public Affairs, Binghamton University, PO Box 6000, Binghamton, NY 13902, 607-777-9169, $\underline{\text { blitz@binghamton.edu }}$ 